\title{
Nueva gobernanza y proceso de paz en el País Vasco norte
}

\author{
New governance and peace process \\ in the northern Basque Country
}

\author{
Eguzki Urteaga \\ Universidad del País Vasco \\ eguzki.urteaga@ehu.eus
}

doi: http://dx.doi.org/10.18543/djhr.2116

Fecha de recepción: 22.12.2020

Fecha de aceptación: 14.05.2021

Cómo citar/Citation: Urteaga, Eguzki. 2021. "Nueva gobernanza y proceso de paz en el País Vasco norte». Deusto Journal of Human Rights, No. 7: 95-126. doi: http://dx.doi.org/10.18543/djhr.2116.

Sumario: Introducción. 1. Fundamentos teóricos y metodológicos.

2. La nueva gobernanza. 2.1. El dispositivo de gobernanza. 2.2. Las características de la gobernanza y sus efectos. 3. El proceso de paz. 3.1. La Conferencia de Aiete y el final de la lucha armada. 3.2. Bake Bidea y la Declaración de Baiona. 3.3. El desarme y la disolución de ETA. 3.4. La construcción de la convivencia. Conclusión. Bibliografía.

Resumen: La nueva gobernanza concebida e implementada en el País Vasco norte desde inicios de los años noventa ha propiciado un cambio progresivo de la cultura política local basada, hoy en día, en el diálogo, la negociación y el acuerdo. Gracias a ella, amplios consensos, tanto políticos como sociales, han sido posibles en temas tan relevantes como la institucionalización del territorio y el proceso de paz. Esto ha posibilitado el hecho de que, en este territorio de únicamente 310.000 habitantes que solo goza de una institución propia desde 2017, se haya producido el desarme y la disolución de ETA, la flexibilización de la política penitenciaria y la construcción progresiva de una convivencia basada en el reconocimiento, la justicia y la reparación para todas las víctimas. No en vano, queda mucho camino por recorrer y los actores implicados en este proceso de paz son perfectamente conscientes de ello.

Palabras clave: Nueva gobernanza, proceso de paz, País Vasco norte.

Abstract: The new governance conceived and implemented on the northern Basque Country since the early 1990s has led to a gradual change in the local political culture based, nowadays, on dialogue, negotiation and agreement. Thanks to this change, broad consensus, both political and social, 
has been possible on such relevant issues as the institutionalization of the territory and the peace process. This fact has made it possible that, in this small territory with a population of 310,000 people, which has only had its own local administration since 2017, there has been disarmament and the dissolution of ETA, the flexibilization of the prison policy and the progressive construction of a coexistence based on recognition, justice and reparation for all the victims. However, there is still a long way to go and the actors involved in this peace process are perfectly aware of it.

Keywords: New governance, peace process, Northern Basque Country. 


\section{Introducción}

¿Cómo explicar que, a pesar de carecer de una institución propia hasta enero de 2017 que además no goza de ninguna competencia en materia de seguridad interior, el País Vasco norte haya dado pasos relevantes en materia de proceso de paz, con el desarme y la disolución de ETA y la posterior flexibilización de la política penitenciaria en el Hexágono? Esta situación es indisociable de la nueva gobernanza elaborada y posteriormente implementada en este territorio desde inicios de los años noventa, que ha desembocado en la constitución progresiva de una nueva cultura política basada en el diálogo, la negociación y el acuerdo (Ahedo y Urteaga 2005).

De hecho, a partir de ese periodo, los poderes públicos galos han manifestado su voluntad de pasar de una lógica de confrontación a una lógica de cooperación entre la organización armada y el Estado francés y, sobre todo, entre la clase política local y la sociedad civil organizada (Urteaga 2020a: 7). Y ello en un contexto marcado por tres fenómenos esenciales:

- En primer lugar, un intenso debate político y académico sobre la noción de gobernanza territorial. De hecho, esta reflexión prospera en un periodo histórico dominado por «la búsqueda de nuevos modos de organización y de gestión territorial, alternativos a las perspectivas territoriales descendientes». Por una parte, la gobernanza territorial alude al desarrollo local, en un periodo caracterizado por la implicación creciente de los actores locales (privados, públicos, asociativos) en las dinámicas de desarrollo, con su capacidad para organizarse, movilizarse, coordinarse y asumir responsabilidades. Por otra parte, las instituciones experimentan una doble evolución: la transferencia de competencias a instancias supranacionales (en el marco de la construcción europea) y regionales (en el marco de la descentralización), y la recomposición de los espacios de ejercicio del poder. Esta recomposición se traduce, a la vez, en una desterritorialización y una reterritorialización (Leloup et al. 2005: 321-323).

- En segundo lugar, la reactivación de la reivindicación a favor de un Departamento Vasco para el País Vasco norte. Esta demanda, formulada desde 1963 por la formación nacionalista Enbata (Urteaga 2004a: 42), a la que se adhieren los actores económicos liderados por la Cámara de Comercio y de Industria de Baiona a partir de1975 (Loyer 2003: 108), forma parte de 
las 110 propuestas de François Mitterrand para las elecciones presidenciales de 1981. Ante la no-implementación de dicha promesa por el mandatario socialista, los actores favorables a un Departamento Vasco crean la Asociación para un Nuevo Departamento en 1983 para informar a la ciudadanía, elaborar una argumentación sólida y llevar a cabo una labor de lobbing. Esta reivindicación conoce un nuevo impulso a inicios de los años noventa, en un panorama singularizado por la implantación electoral creciente del nacionalismo vasco, lo que obliga a los partidos de gobierno galos a apropiarse de estas temáticas para poder ser elegidos, como consecuencia de un modo de escrutinio mayoritario a dos vueltas (Urteaga 2007: 185, 203).

- En tercer lugar, el declive progresivo de la lucha armada practicada por Iparretarrak (Moruzzi y Boulaert 1988; Bidegain 2007). A ese propósito, la detención de Bidart, líder de esta organización, y de otros cuatro miembros de Iparretarrak, el 20 de febrero de 1988, supone un punto de inflexión. A partir de entonces, Iparretarrak cometerá un reducido número de atentados, tales como el asalto contra el Comité de turismo de Biarritz (1988), el ataque contra la Agencia tributaria de Baiona (1989) o el atentado contra la Agencia de EDF-GDF de Orthez (1991). Tras la tregua decretada en 1998 para no poner en peligro el proceso resultante de la Declaración de Lizarra-Garazi, Iparretarrak reivindica su última acción, de carácter simbólico, en enero de 2003 (Urteaga 2007: 223). Su renuncia a la lucha armada es igualmente fruto de la creación de partidos nacionalistas vascos a partir de mediados de los años ochenta cuyo objetivo principal es conseguir la mayor implantación electoral posible (lo que resulta incompatible con la continuación del uso de la violencia con fines políticos), los buenos resultados electorales cosechados por estas formaciones en las diferentes elecciones (Urteaga 2007: 139-140 y 153154), y las divisiones internas que genera la lucha armada practicada por la organización independentista en el seno del movimiento nacionalista vasco y, más precisamente, entre Ezkerreko Mugimendu Abertzalea y Euskal Batasuna.

El cambio de orientación de las autoridades francesas se traduce en el lanzamiento de la prospectiva País Vasco 2010 (Club de Prospective Pays Basque 1994) que moviliza a las instituciones y a las fuerzas dinámicas de la sociedad vasca. Entre 1992 y 1993, elaboran de manera conjunta un diagnóstico pormenorizado del territorio y 
unos escenarios prospectivos con horizonte 2010 en función de las decisiones tomadas por las administraciones públicas. Ningún apartado alude a la violencia política y a sus consecuencias, sinónimas de presos y víctimas, ni tampoco a cuestiones relacionadas con la memoria y la convivencia. A pesar de ello, este informe supone una concienciación de todos los actores implicados sobre la necesidad de concebir y aplicar unas políticas estructurantes y ambiciosas a escala del País Vasco norte (Urteaga 2020a: 8).

Esto implica poner en marcha una nueva gobernanza que consiste en una manera novedosa de elaborar, implementar y evaluar las políticas públicas donde todos los actores concernidos, tanto institucionales como sociales, efectúan un diagnóstico de la situación, definen unos objetivos a medio y largo plazo, y precisan las acciones que permiten alcanzar estos fines (Urteaga y Ahedo 2004). Para ello, es imprescindible crear un dispositivo de gobernanza articulado en torno al binomio Consejo de Desarrollo del País Vasco - Consejo de Electos del País Vasco. Mientras que el primero reúne a los representantes de las empresas, cooperativas, asociaciones y personalidades cualificadas, el segundo agrupa a los principales cargos electos del territorio, de todos los niveles políticoadministrativos y de todas las sensibilidades políticas.

Esta nueva gobernanza, que se perfecciona a lo largo del tiempo gracias a un proceso de aprendizaje continuo, se caracteriza por 1) el reconocimiento de los actores de la parte adversa como interlocutores legítimos con los cuales es posible e incluso necesario colaborar; 2) el conocimiento mutuo de los agentes involucrados como consecuencia de un diálogo constante, sosegado y respetuoso; 3) la concertación permanente entre los actores implicados; 4) la negociación entre los socios de cara a llegar a un acuerdo sobre las medidas a implementar; 5) el respeto de las decisiones tomadas de manera consensuada; 6) la aplicación efectiva de las decisiones tomadas; y, 7) la evaluación compartida de las acciones acordadas y posteriormente aplicadas (Urteaga 2017: 114).

La implementación de esta nueva gobernanza, además de desembocar en la elaboración del proyecto de territorio País Vasco 2020 y la aprobación de contratos territoriales sucesivos (Urteaga 2020a), ha dado lugar, con el transcurso del tiempo y de manera progresiva, a la modificación de la cultura política local. Esta ha surtido efectos tangibles en materia de institucionalización del territorio, con la demanda unánime de una Colectividad Territorial a estatus particular (Collectivité territoriale Pays Basque 2013) y la creación consensuada de la Comunidad de Aglomeración del País Vasco, y en el ámbito del proceso de paz. 
En efecto, además de la participación de los principales actores políticos, sindicales y asociativos del País Vasco norte en la Conferencia de Aiete en 2011 (Urteaga 2020b: 100), una amplia representación de estos actores negocia y aprueba la Declaración de Baiona en 2014 (Bake Bidea 2014). Posteriormente, bajo la presión de la sociedad civil organizada y tras la operación de Luhusoa (Esnaola 2017), el Estado galo accede al desarme de ETA y a la organización de un acto multitudinario en Baiona, y a su posterior disolución escenificada en la Conferencia Internacional de Arnaga (Bake Bidea 2021c) en Kanbo (L'Express 2018). Estos pasos van de la mano de la flexibilización de la política penitenciaria por el gobierno francés, tras las movilizaciones impulsadas por los Artesanos de la Paz y las negociaciones llevadas a cabo por la delegación de Iparralde, encabezada por Jean-René Etchegaray y el ministerio de Justicia francés (Bake Bidea 2021a). Esta flexibilización toma la forma del acercamiento de los presos vascos a cárceles cercanas al territorio y a la supresión del estatus Detenidos Particularmente Señalados (DPS) a numerosos reclusos, lo que propicia el cambio de grado (Observatoire International des Prisons 2014).

\section{Fundamentos teóricos y metodológicos}

Precisando el marco conceptual y metodológico en el cual se sitúa este trabajo, por una parte se halla la noción de gobernanza territorial (Pasquier et al. 2007), que se distingue del concepto de gobernanza mundial. Este último irrumpe en un contexto de globalización marcado por una interdependencia creciente entre los países, que supone la elaboración de reglas a escala mundial cuyo respeto está garantizado por instituciones supranacionales (Diez et al. 2011). Se diferencia igualmente de la noción de buena gobernanza, que alude a aquella que busca el interés general fomentando el crecimiento económico, la cohesión social, la estabilidad política y la seguridad ciudadana. Asimismo, lucha contra la corrupción y el blanqueo de capitales, propicia el pleno respeto del Estado de derecho, mejora la transparencia y elabora leyes eficaces como fundamento para el funcionamiento de las instituciones democráticas (OSCE 2021).

En cambio, el presente enfoque centra su atención en una visión territorial de la gobernanza, poniendo de manifiesto las profundas transformaciones que ha conocido la gobernanza en el ámbito local, dado que hace intervenir una red múltiple y compleja de actores y de instituciones que interactúan y cooperan entre sí, de manera más o menos armoniosa y colaborativa (Stoker 1998). Todo lo cual se traduce 
en una interdependencia entre los poderes públicos y la sociedad civil organizada a la hora de llevar a cabo una acción colectiva.

Pecqueur (2000) define la gobernanza territorial como un proceso institucional y organizacional de construcción de una puesta en compatibilidad de los diferentes modos de coordinación entre actores geográficamente próximos, de cara a resolver los problemas territoriales. De su parte, Bourdin (2000: 42-43) la define como la «manera de abordar la cuestión del gobierno que no prioriza el arte de gobernar o las técnicas para llevar a cabo la acción, sino las relaciones entre dirigentes y dirigidos, especialmente entre la sociedad civil y las instituciones públicas».

Precisamente, uno de los ejes de reflexión que se desarrolla en Francia en aquel momento, además de la relación entre los sectores público y privado y la articulación entre los diferentes centros de decisión en virtud de los principios de subsidiaridad y descentralización (Chautard et al. 2003), gira en torno a las relaciones entre los poderes públicos locales y la sociedad civil organizada, por mediación de la consulta y de la concertación. Con el transcurso del tiempo, ha adquirido una gran importancia tanto en la legislación como en la acción pública, especialmente en lo que se refiere a las cuestiones de ordenación y desarrollo del territorio (Urteaga 2020a) y de urbanismo (Le Galès 1995; Jouve 2003).

Esta gobernanza territorial ha adquirido una forma específica en el País Vasco norte, dado que existe una fuerte identidad territorial basada en una lengua, una cultura y una historia propias, lo que conducirá el legislador a reconocer posteriormente el País Vasco norte como un país (Légifrance 1999), es decir como un territorio dotado de unas características originales y de un proyecto de territorio. A todo ello se añade el dinamismo del movimiento nacionalista vasco en las esferas culturales, sociales y económicas, así como la implantación electoral creciente de las formaciones nacionalistas vascas que aspiran a involucrarse plenamente en las instituciones (Urteaga 2004a). Por último, resulta de la reactivación de la reivindicación a favor de un Departamento Vasco que goza del apoyo de amplios sectores de la sociedad vasca (Chaussier 1997; 1998). Todo ello explica, en gran medida, la forma peculiar tomada por la gobernanza territorial en Iparralde.

Por otra parte, la noción de proceso de paz hace referencia al «esfuerzo para lograr un acuerdo que ponga fin a la violencia, así como para implementarlo, mediante negociaciones que pueden requerir la mediación de terceros» (Fisas 2010, 4). Con esta definición inicial se destaca la idea de que es 
un proceso, no es un momento puntual, (...) en el que intervienen todos los actores afectados, en un esfuerzo colectivo para (...) alcanzar acuerdos que permitan acabar con la situación anterior, dominada por la violencia y el enfrentamiento armado, para dar paso, mediante el diálogo y el consenso, a pactos o acuerdos que pongan fin a la violencia física, y, mediante la implementación de los acuerdos, iniciar una nueva etapa de progreso y desarrollo que permita superar igualmente las violencias estructurales que propiciaron el surgimiento del conflicto (Fisas 2010: 4).

Un proceso de paz incluye:

la fase de negociación y de mediación, pero la trasciende completamente, al referirse también, y de manera esencial, al cumplimiento de lo acordado. De ahí que el proceso de paz vaya más allá del acuerdo o pacto de paz, que siendo éste un momento cumbre y sin duda el más visible, no es más que el punto de partida de unas etapas decisivas en las que se verá si realmente el cese de la violencia es capaz de generar una nueva situación de paz positiva, entendida como de prosperidad, armonía, desarrollo humano, crecimiento personal y justicia social, entre otros aspectos (Fisas 2010: 4-5).

Los procesos de paz se enfrentan a ciertos riesgos. El primero de ellos es «la falta de convicción de los actores». Un segundo factor de riesgo consiste en «menospreciar o ignorar los apoyos externos, sean del tipo que fueren». Habitualmente "se necesita del concurso de mediaciones, garantes, verificadores o incentivadores externos, y no es recomendable prescindir de estas aportaciones». Otro riesgo habitual es generar más expectativas de las razonables. Y, por último, otro riesgo es «el surgimiento de disidencias y divisiones en los grupos que entran en una negociación» (Fisas 2010: 18).

Por otra parte, existen diferentes modelos de proceso de paz, determinados por el tema de fondo a discusión: «de reinserción, de reparto del poder, de intercambio, de medidas de confianza y de autogobierno» (Fisas 2010: 6). Asimismo, hay modelos en los que la sociedad civil tiene un papel protagónico (al crearse estructuras participativas que permiten darle voz en los primeros momentos o en fases avanzadas del proceso), mientras que en otros la voz cantante queda relegada a los actores primarios (gobierno y grupos armados), más los posibles facilitadores.

El proceso de paz vasco se distingue fundamentalmente por su carácter unilateral, dado que no resulta de una negociación bilateral entre dos Estados (español y francés) y una organización armada (ETA), 
y por el papel relevante desempeñado por la sociedad civil organizada en colaboración con las instituciones y los cargos electos locales (Foro Social 2017).

En cuanto a la metodología de análisis seguida es esencialmente comprensiva, en la medida en que incide en las percepciones y vivencias de los actores involucrados para comprender sus opiniones, actitudes y comportamientos De hecho, Max Weber define la sociología como una ciencia empírica que desea comprender la acción social a través de la interpretación y, de ese modo, explicar causalmente su desarrollo y sus efectos. Esto significa que «la tarea sociológica consiste en comprender el sentido que motiva estas acciones específicas durante el transcurso de las cuales los individuos toman en consideración el comportamiento del prójimo. [Esto implica que] el sociólogo deba explicar la secuencia de los hechos en la cual [se desarrollan] estas acciones» (Lallement 2015). Más concretamente, se ha utilizado básicamente el análisis documental centrado en múltiples investigaciones llevadas a cabo desde inicios de los años noventa, y que ha utilizado esencialmente métodos cualitativos (Desjeux et al. 2019), como la observación participante (en el Consejo de la Lengua Vasca y el Consejo de Desarrollo del País Vasco), la entrevista en profundidad (con los actores locales, miembros de las instancias de concertación locales) (Munarriz 1992), el análisis documental (de estudios prospectivos, informes sectoriales, evaluaciones de políticas públicas, contratos territoriales, declaraciones, artículos de medios de comunicación, etc.).

\section{La nueva gobernanza}

A inicios de los años noventa, el contexto político local se caracteriza por el declive progresivo de la lucha armada practicada por Iparretarrak y por la progresión electoral del nacionalismo vasco (Urteaga 2007). Además, los nacionalistas vascos, muy activos en las cooperativas, los sindicatos, las asociaciones y los movimientos sociales, padecen una escasa representación institucional, dado que el modo de escrutinio mayoritario a dos vueltas perjudica las formaciones que carecen de verdaderos aliados, y no obtienen por sí solos los resultados suficientes para poder vencer en la segunda vuelta. Por ello, los poderes públicos van a tratar de integrar a estos actores en el juego político e, incluso, institucional (Urteaga 2020a: 13).

Los poderes públicos, encabezados por el Estado galo, desean propiciar la cooperación entre las instituciones y las fuerzas dinámicas de la sociedad vasca y, por ello, como primer paso, lanzan la 
Prospectiva País Vasco 2010 (Club de Prospective Pays Basque 1994). Un trabajo que es presentado públicamente en el foro de Baiona del 4 de diciembre de 1993, y que da lugar a tres documentos. El primero efectúa un diagnóstico de los distintos aspectos (económicos, políticos, sociales, culturales, institucionales, etc.) de la situación presente. El segundo realiza un análisis estructural, identificando las variables de cambio, las tendencias de fondo y los principales retos de futuro. $Y$ el tercer documento realiza una labor prospectiva, describiendo los seis posibles escenarios futuros en función de las decisiones tomadas.

Como consecuencia de la elaboración y posterior publicación de los tres documentos que componen la prospectiva País Vasco 2010, los ejecutivos de los diferentes niveles político-administrativos y los cargos electos locales van a tomar conciencia de la imperiosa necesidad de dar continuidad a este informe de manera urgente, dada la apremiante demanda de la sociedad vasca. Razón por la cual se inicia una reflexión entre todos los actores concernidos para dotar a este territorio de un nuevo dispositivo de gobernanza (Urteaga 2020a: 33). Se trata, por una parte, de concebir y de llevar a la práctica una política pública integral a escala del País Vasco norte y, por otra parte, de crear unas estructuras de concertación perenes para imaginar una nueva manera de elaborar, implementar y evaluar las políticas públicas. Lo cual desemboca, a su vez, en la creación del binomio Consejo de Desarrollo del País Vasco - Consejo de Electos del País Vasco, y en la puesta en marcha de una nueva gobernanza (Urteaga y Ahedo 2004: 177).

\subsection{El dispositivo de gobernanza}

El Consejo de Desarrollo del País Vasco (CDPV), constituido en julio de 1994, tiene como objeto contribuir al desarrollo global, coherente y armonioso del País Vasco norte, a la ordenación del territorio y a la cooperación transfronteriza. Se trata de un órgano asesor cuya misión consiste en la realización de estudios y encuestas, la identificación de opciones de desarrollo, la propuesta de orientaciones y la formulación de sus puntos de vista sobre los proyectos y las decisiones planteados (Conseil de Développement du Pays Basque 1994: 1).

En este sentido, su capacidad de acción se centra en la dinamización y el asesoramiento en las fases de elaboración, implementación y evaluación de las políticas públicas. Desde sus inicios, su rol es fundamental en 1) la realización de un diagnóstico preciso y la identificación de las problemáticas esenciales del territorio; 2) la elaboración de propuestas y, 3) la valoración de políticas públicas 
(Urteaga y Ahedo 2004: 104). La influencia de esta entidad hace depender su fuerza y, en parte, su legitimidad, de la permeabilidad a sus demandas de las administraciones públicas del Estado, de la Región, del Departamento y de los Ayuntamientos (Conseil de Développement du Pays Basque 2001: 4).

La estructura del Consejo de Desarrollo se articula en torno a la Asamblea plenaria, el Consejo de dirección y la Secretaría general (Conseil de Développement du Pays Basque 1994: 2-3). La Asamblea es, según los estatutos, la instancia soberana que reúne a todos los miembros del Consejo de Desarrollo. Sus miembros se reparten en cinco grupos: los electos, los actores socioeconómicos, los agentes de la comunidad educativa, los representantes institucionales y las personalidades cualificadas. El Consejo de dirección, por su parte, es la instancia dirigente del Consejo de Desarrollo y está compuesto por 26 miembros. Por último, la Secretaría general es la instancia de gestión del Consejo de Desarrollo, compuesta por el presidente del Consejo y, al menos, un vicepresidente, un tesorero y un secretario. El presidente no puede pertenecer al grupo de los electos.

La composición de las instancias del CDPV traduce la importancia concedida a los cargos electos, a los agentes sociales y a los representantes de la sociedad civil organizada, y la presencia notable de personalidades que comparten las ideas básicas del nacionalismo vasco. Este componente se refleja en la presidencia de la instancia de concertación, ya que Ramuntxo Camblong ostenta el cargo.

La relación de fuerzas favorable al nacionalismo vasco en el Consejo de Desarrollo, especialmente en sus inicios, no responde tanto al componente partidista de sus miembros, dado que la gran mayoría no pertenece a ninguna formación política, sino al rol relevante desempeñado por estas personas, a menudo a título individual, en la vida empresarial, sindical y asociativa de Iparralde. No obstante, existe una clara voluntad de los poderes públicos para que los nacionalistas vascos puedan acceder a los círculos de reflexión, debate y decisión que conciernen el territorio (Urteaga y Ahedo 2004: 105-106).

El Consejo de Desarrollo forma un binomio con el Consejo de Electos (CEPV) que se constituye en febrero de 1995. Según sus estatutos, consta de 21 consejeros generales, de 4 consejeros regionales que carecen de un mandato departamental, de los parlamentarios estatales y europeos que no acumulan ningún mandato departamental o regional, y de 36 representantes elegidos por el Biltzar (Urteaga 2017: 84).

El CEPV está dirigido por un Consejo de administración compuesto por 20 miembros elegidos para tres años. Su función consiste en 
convocar a la Asamblea general, preparar sus reuniones, determinar el orden del día, así como elegir el presidente y el secretario. En sus inicios, los cargos de dirección del CEPV fueron ocupados por "grandes electos». Es el caso de Jean-Jacques Lasserre, presidente del Consejo de Electos y vicepresidente del Consejo general de los PirineosAtlánticos; un actor clave de la gobernanza local. Paralelamente, la presencia de los electos de las zonas rurales es significativa. De hecho, la composición de la Asamblea general reserva 23 plazas a los representantes de los municipios rurales de Zuberoa y Baja Navarra. Y 7 de los 20 representantes del Consejo de administración son del interior. En cambio, la presidencia y las tres quintas partes de los cargos de dirección pertenecen a electos que provienen del litoral. A su vez, una tercera parte de los miembros del Consejo de administración está constituida por electos de las tres ciudades de la aglomeración de Baiona (Urteaga y Ahedo 2004: 110-111).

Esta instancia goza de una innegable legitimidad fruto de la elección por sufragio universal directo de sus miembros y de su carácter representativo del territorio (Conseil de Développement du Pays Basque 2001: 6). Y su objeto consiste en «elaborar, a escala del País Vasco [norte], un proyecto de territorio y un Esquema de Ordenación» así como "constituir una fuerza de propuesta y de intervención ante instituciones, [tales como] el Consejo general, el Consejo regional, el gobierno [galo] o la Unión europea» (Conseil des Elus du Pays Basque 1995: 1).

En este sentido, el CEPV desempeña un rol preponderante en la negociación para la implementación de las políticas públicas a nivel del territorio gracias a su capacidad de presión sobre los diferentes niveles de la administración pública. Ello le confiere una posición clave en las relaciones interinstitucionales que se producen en el País Vasco norte de cara a decidir las modalidades de aplicación de las medidas contempladas en el Esquema. Paralelamente, el Consejo de Electos goza de capacidad de acuerdo con los diferentes ministerios y firma, en nombre del territorio, los diferentes convenios que financian los proyectos (Urteaga y Ahedo 2004: 112).

\subsection{Las características de la gobernanza y sus efectos}

Las instancias de concertación permiten la puesta en práctica de la nueva gobernanza, que se traduce en una manera original de hacer política, consistente en asociar a todos los actores locales concernidos por una problemática determinada (tal como la lengua vasca, la 
creación cultural o el desarrollo económico), para que la elaboración, la implementación y la evaluación de las políticas públicas sea el fruto de una concertación entre los actores institucionales, socioeconómicos y asociativos.

De hecho, hasta entonces, las políticas públicas puestas en marcha en Iparralde estaban impulsadas por cargos electos, posteriormente concebidas por altos funcionarios y finalmente validadas por los ejecutivos de las diferentes instituciones sin consultar previamente a los principales actores de la sociedad civil organizada, de modo que las políticas públicas no respondían realmente ni a sus necesidades ni a sus demandas. Por ello era preciso diseñar una nueva manera de gobernar basada en el reconocimiento de los actores implicados, el conocimiento mutuo de los mismos, una amplia concertación, una negociación a lo largo de todo el proceso, unas decisiones aceptadas, una aplicación efectiva y una evaluación compartida (Urteaga y Ahedo 2004: 177).

Más precisamente, la primera característica de esta nueva gobernanza consiste en el reconocimiento de los actores pertenecientes a la parte adversa como actores legítimos con quienes es posible e incluso imprescindible colaborar. Efectivamente, el inicio de los años noventa coincide con la voluntad de las administraciones públicas en general, y del Estado galo en particular, de modificar en profundidad las modalidades de fabricación de las políticas públicas reuniendo a actores que estaban hasta entonces excluidos del juego político, puesto que el País Vasco norte no disponía de ningún diputado ni consejero regional, de un consejero general, de algunos alcaldes de pequeños municipios y de varios electos municipales, mayoritariamente en la oposición, que se reclamaban del nacionalismo vasco (Urteaga 2007). Por consiguiente, los poderes públicos se esfuerzan inicialmente en reconocer públicamente a los sindicatos, las federaciones y otras asociaciones como actores ineludibles del debate público con los cuales desea intercambiar y luego cooperar. Posteriormente, una reflexión es llevada a cabo para precisar las modalidades que debe tomar esta voluntad, lo que desemboca en el proyecto de creación de los diferentes Consejos y, en concreto, del binomio CDPV-CEPV.

Conviene recordar que, hasta la fecha, la exclusión política de toda una franja de actores locales los había llevado a recurrir a modos de acción conflictivos, e incluso ilegales aunque no-violentos, para hacer escuchar su voz. Así, los años setenta y ochenta están jalonados por movilizaciones y protestas para el reconocimiento de las escuelas que practican la inmersión lingüística en euskera, la reivindicación de la amnistía para los presos vascos o la denuncia del turismo masivo. En otros términos, al estar políticamente marginados e institucionalmente 
infra-representados, los actores de la sociedad civil organizada y las formaciones nacionalistas vascos no estaban reconocidos como interlocutores y socios válidos.

El segundo rasgo de esta nueva gobernanza es el conocimiento mutuo de los actores locales, dado que muchos años de viva confrontación y de ausencia de comunicación directa contribuyeron a hacer emerger prejuicios, estereotipos y representaciones preconcebidas. De hecho, al carecer de vínculos personales y siendo sus únicos contactos sinónimos de enfrentamientos y de agresiones verbales e incluso físicas, no es de sorprender que los actores locales tuviesen imágenes completamente deformadas unos de otros.

Para las asociaciones, los poderes públicos eran los representantes de un Estado jacobino que recurría sistemáticamente a la represión y obstaculizaba cualquier iniciativa cuya finalidad fuese garantizar el desarrollo económico del territorio, el auge de la enseñanza bilingüe o la institucionalización del País Vasco norte. Y cualquier discurso o gesto de apaciguamiento y de conciliación sería una trampa tendida a fin de persuadir y calmar las reivindicaciones legítimas del pueblo vasco (Urteaga y Ahedo 2004: 178).

Para las instituciones públicas, al contrario, los actores de la sociedad civil organizada, presuntamente radicales y excesivos, tendrían unas aspiraciones separatistas que pondrían en peligro la unidad de la República francesa. Estos actores recurrirían a modos de acción violentos o, al menos, de desobediencia civil (Zin 2010; Cervera-Marzal 2013), cuya única finalidad sería provocar tensiones en la sociedad vasca para doblegar a las instituciones democráticas. Y cualquier propósito moderado estaría considerado como sospechoso, puesto que detrás de las demandas de creación de una institución propia se escondería el proyecto de acceder a la independencia.

Por todo ello, uno de los principales méritos de la creación de estos Consejos fue permitir un mejor conocimiento mutuo de las personas involucradas. Tanto unos como otros se dieron cuenta de que sus supuestos "adversarios» e incluso «enemigos» podían ser personas razonables con las cuales es posible dialogar y, luego, llegar a acuerdos, por su disposición a hacer concesiones. A medida que los encuentros se suceden, las máscaras caen, favoreciendo unos intercambios más directos y sinceros, lejos de los discursos habituales. Amistades o, al menos, afinidades surgen entre ciertas personas que tenían más puntos en común de lo que pensaban previamente.

La tercera especificidad de esta nueva gobernanza estriba en la concertación permanente entre los actores presentes. En efecto, hasta los años noventa, las decisiones tomadas unilateralmente por 
los poderes públicos respondían a las concentraciones o las ruedas de prensa, de manera que el intercambio de puntos de vista se hacía por mediación de la protesta y de los medios de comunicación. La concertación, propiamente dicha, era casi inexistente, y cuando se producía, estaba reservada a ciertas personas y temáticas. En esta óptica, la creación de los diferentes Consejos permitió tanto a asociaciones como a instituciones conocer los proyectos de la parte adversa antes de que fueran desvelados en la esfera pública pero también y, sobre todo, intercambiar y debatir sobre su pertinencia. Por ejemplo, el Esquema de Ordenación y Desarrollo del País Vasco es elaborado entre 1995 y 1997, de manera concertada entre los actores concernidos. De hecho, diversas comisiones temáticas compuestas por representantes de profesiones, asociaciones, sindicatos e instituciones se reúnen regularmente a fin de elaborar un diagnóstico exhaustivo, fijar unos objetivos a medio plazo y precisar las estrategias a seguir de cara a alcanzar estos fines. Como consecuencia de ello, las recomendaciones contenidas en el Esquema de Ordenación son objeto de un amplio consenso entre los actores locales y no suscitan ninguna reacción de desaprobación notable; más aún teniendo en cuenta que la concertación procura a las personas la sensación de haber sido consultadas y escuchadas, evitando cualquier forma de rechazo, fruto de una impresión de exclusión.

La cuarta particularidad de esta gobernanza local está constituida por la negociación entre los socios cuya finalidad es llegar a un acuerdo sobre las propuestas que merecen ser implementadas $y$, por lo tanto, financiadas. Las discusiones aluden a la elección de la acción, a la cuantía de la financiación, a la naturaleza de la Dirección de Obra Pública y del obrador, sin olvidar los plazos de concreción. Estas negociaciones, a veces duras, dan lugar a intercambios, cuyo fin es convencer a su interlocutor con argumentos pertinentes (Urteaga y Ahedo 2004: 179-180). Es lo que acontece en el periodo de negociación del Esquema de Ordenación que se desarrolla entre 1998 y 2000 y que se salda con la firma del Convenio Específico en diciembre de 2000. Dicho Convenio tiene en cuenta una parte significativa de las preconizaciones de dicho Esquema, este último pudiendo ser exhaustivo y siendo objeto de una actualización e incluso de un análisis profundizado de los ámbitos no explorados hasta entonces (Conseil de Développement du Pays Basque 2000).

Para llegar a este resultado, el Consejo de Desarrollo, en estrecha colaboración con el Consejo de Electos encargado de la negociación, recurre a diversas estrategias: convencer los poderes públicos de la pertinencia de ciertos proyectos, poner de manifiesto los riesgos de 
conflicto y de movilización de la sociedad civil organizada en caso de rechazo, o mostrarse dispuesto a renunciar a una recomendación a cambio de la contractualización de otra propuesta.

Las instituciones, por su parte, no dudan en recordar, de manera más o menos explícita, que, en última instancia, el poder decisorio les pertenece y no conviene depositar demasiadas esperanzas en una modificación inminente de la legislación imperante. En otros términos, las propuestas deben situarse en el marco institucional vigente sin pretender transformarlo. Más precisamente, los poderes públicos aceptan la aprobación de una propuesta, con la condición de que el Obrador sea público, a la imagen de la acción del Convenio Específico relativa a la sensibilización al aprendizaje de la lengua vasca en la escuela cuya ejecución es confiada al ministerio de Educación. De la misma forma, las instituciones aceptan la creación del Consejo de la Lengua Vasca con la condición expresa de que este sea de carácter consultivo.

El quinto rasgo de la gobernanza local consiste en la aceptación de las decisiones tomadas de manera consensuada. Efectivamente, el proceso de negociación desemboca en la toma de decisiones sobre los proyectos que serán seleccionados y sus modalidades de desarrollo. Relativos a cuestiones económicas, culturales o sociales, el método es sensiblemente el mismo, puesto que, una vez alcanzado el acuerdo, la decisión es ratificada inmediatamente o validada posteriormente. No obstante, conviene subrayar la complejidad del fenómeno, en la medida en que existe una diferencia notable entre los poderes de decisión formal e informal. En teoría, los diferentes Consejos solo gozan de un poder consultivo y formulan recomendaciones dirigidas a los poderes públicos. En realidad, a partir del instante en que estos Consejos se ganan la confianza de las instituciones, orientan en buena medida, las decisiones de estas últimas. De hecho, estos Consejos están encargados de la realización de diagnósticos, de la puesta de manifiesto de obstáculos y, sobre todo, de la formulación de recomendaciones. Más aún, negocian a veces estas propuestas, lo que les confiere un poder innegable, puesto que intervienen a lo largo de todo el proceso de elaboración de los proyectos. Por ello, un buen número de proyectos son validados tal cual o tras pequeñas modificaciones (Urteaga y Ahedo 2004: 180-181). Pero, para que así sea, estos Consejos deben beneficiarse de la confianza de los poderes públicos, lo que supone cuidar las formas y mantener relaciones amables con las instituciones. Esto pasa por el hecho de invitarlas sistemáticamente a las reuniones a fin de asociarlas a las iniciativas tomadas y a los eventos organizados, convidarlas a las ruedas de prensa durante las cuales se presentan los proyectos a los medios de comunicación, o no agredirlas 
verbalmente en las reuniones de los Consejos de administración. La construcción de semejante confianza exige dedicarle tiempo e implica paciencia y perseverancia a fin de superar los sobresaltos y gestionar las impaciencias que surgen inevitablemente. En cambio, si la confianza no existe o se desvanece consecutivamente a unas declaraciones realizadas, unas acciones llevadas a cabo o unos nombramientos efectuados, la capacidad de influir en las decisiones de estos Consejos disminuye notablemente.

La sexta característica de esta gobernanza local no es otra que la aplicación efectiva de las decisiones tomadas. Así, una vez firmado el Convenio Específico, se inicia la fase de implementación de las acciones, lo que supone discusiones con los actores designados o susceptibles de serlo. Por ejemplo, la creación del Consejo de la Lengua Vasca, que es la primera acción del apartado lingüístico de dicho Convenio, es precedida de numerosos intercambios dialécticos a fin de determinar si este Consejo debía formar parte del Instituto Cultural Vasco o si debía gozar de total independencia. Las asociaciones que operan en el ámbito lingüístico son favorables a la segunda opción, estimando que la amalgama entre lengua y cultura vascas se hace en detrimento de la lengua propia del territorio, mientras que el Instituto mencionado es partidario de la primera opción, considerando que la lengua y la cultura vascas son indisociables, teniendo en cuenta el hecho de que una separación sería perjudicial para Instituto, que perdería una parte de sus competencias. Estas discusiones, que se prolongan durante varios meses retrasando la creación del Consejo de la Lengua Vasca, desembocan en la victoria de las asociaciones lingüísticas. En resumidas cuentas, la aplicación de las acciones contractualizadas es efectiva de manera general, aunque dependa en gran parte de la voluntad tanto de las instituciones como de las asociaciones, de las posibilidades presupuestarias de las administraciones públicas y del contexto político; sabiendo que un periodo de tensiones es a veces propicio para el avance de los proyectos, dado que los poderes públicos desean demostrar que obran efectivamente a favor del desarrollo económico y de la revitalización de la lengua vasca sin que sea necesario proceder a cambios normativos.

La séptima y última distinción de esta nueva gobernanza local es la evaluación compartida de las políticas públicas implementadas en general, y de las acciones acordadas en particular. Así, una de las misiones del Consejo de la Lengua Vasca ha consistido precisamente en evaluar las políticas implementadas a fin de promover y apoyar la lengua vasca (Urteaga 2004). Este Consejo ha tenido la responsabilidad de proceder a la evaluación del apartado lingüístico del Convenio Específico 
a fin de permitir a la Dirección de Obra Pública de la Política Lingüística, encargada del dossier, tener un perfecto conocimiento del nivel y de las modalidades de aplicación de las acciones que figuran en ese apartado. Esta evaluación consta de cinco fases: 1) recordar la naturaleza de la acción aceptada, precisando las medidas y la financiación previstas; 2) enunciar el nivel de aplicación de la acción, especificando lo que ha sido realizado y con qué dinero; 3) poner de manifiesto los obstáculos y los problemas que han podido surgir; 4) formular propuestas que permitan superar estas dificultades y encontrar soluciones; $y, 5)$ poner énfasis en las nuevas necesidades aparecidas entre 2001 y 2003 que eran difícilmente previsibles en el momento de la ratificación del Convenio Específico. Esta evaluación se inscribe en una valoración más global concerniente el Convenio Específico en su conjunto y cuya responsabilidad es confiada al Consejo de Desarrollo del País Vasco. En efecto, además del apartado lingüístico, el turismo, la formación o la cultura son analizados de cara a tener una visión integral del nivel y de las modalidades de implementación de dicho Convenio. En ese sentido, estas evaluaciones, que son realizadas de manera concertada con todos los actores concernidos, favoreciendo así el consenso y la aceptación, son unos instrumentos valiosos que influyen en las reorientaciones de las políticas públicas y dan cuenta de esta nueva gobernanza que se ejerce a diario en el País Vasco norte (Urteaga y Ahedo 2004: 182-183).

La implementación de esta nueva gobernanza surte efectos tangibles, tanto directos como indirectos. Por una parte, permite la elaboración de sendos proyectos de territorio, con el Esquema de Ordenación y Desarrollo (Conseil de Développement du Pays Basque 1996) y País Vasco 2020 (Conseil de Développement du Pays Basque 2007), que desembocan, tras unos periodos de negociación y de posterior acuerdo, en la aprobación de contratos territoriales, con el Convenio Específico País Vasco 2001-2006 (Convention Spécifique Pays Basque 2000) y, luego, los Contratos Territoriales del País Vasco 2007-2013 (Contrat territorial Pays Basque 2007-2013 2008) y 20152020 (Contrat territorial Pays Basque 2015-2020 2015). Por otra parte, contribuye a alcanzar amplios consensos sobre temas tan sensibles como la institucionalización del territorio o el proceso de paz. Más allá, propicia la modificación progresiva de la cultura política local basada, hoy en día, en el diálogo, la negociación y el acuerdo.

1 A pesar de las virtudes innegables y de los resultados tangibles de la nueva gobernanza, ésta se enfrenta a una serie de límites, tales como su escasa incidencia en la legislación en vigor, la ausencia de poder decisorio de las instancias de concertación, la composición heterogénea de estas entidades, la aplicación parcial de 


\section{El proceso de paz}

El cambio paulatino de la cultura política local, como fruto de la nueva gobernanza puesta en marcha desde mediados de los años noventa, ha permitido realizar avances sustanciales en materia de proceso de paz (Murua 2015, 2016). Desde la Conferencia de Aiete y el final de la lucha armada practicada por ETA, se ha ratificado la Declaración de Baiona y se ha procedido al desarme y a la disolución de ETA. A su vez, se ha progresado en la construcción de la convivencia con la flexibilización de la política penitencia y el reconocimiento de todas las víctimas.

\subsection{La Conferencia de Aiete y el fin de la lucha armada}

El año 2011 marca un punto de inflexión en el panorama político vasco con el anuncio del final de la actividad armada practicada por ETA desde 1968. Todo acontece en algunos meses, siguiendo una planificación precisa resultado de una negociación previa. Así, tras la Declaración de Bruselas del 29 de marzo de 2010 (a la que se adhiere una veintena de personalidades entre las que figuran cinco Premios Nobel de la Paz), un grupo de expertos internacionales especializados en procesos de paz se involucra para "acelerar, facilitar y favorecer la normalización del País Vasco» y propiciar la declaración de un cese al fuego permanente y averiguable de ETA, que acontece el 1 de enero de 2011. Para que la paz sea duradera, se celebra una Conferencia Internacional para la resolución del conflicto en San Sebastián el 17 de octubre». Al día siguiente, varios dirigentes de la antigua Batasuna piden a ETA el final definitivo de la lucha armada (Enbata 2011).

La Conferencia Internacional de Aiete está organizada por Lokarri y el Grupo Internacional de Contacto (GIC) liderado por el abogado surafricano Brian Currin. Eminentes personalidades, entre las cuales se halla el antiguo Secretario general de la Organización de Naciones Unidas, Kofi Annan, apadrinan este acto histórico. Los exprimer ministros Bertie Ahern y Gro Harlem Brutland; el exministro del Interior francés, Pierre Joxe; el ex-director de gabinete de Tony Blair, Jonathan Powel y, por último, el líder del Sinn Féin, Gerry Adams», están igualmente presentes. El expresidente de Estados Unidos, Jimmy Carter,

las recomendaciones formuladas por estas instancias, el alargamiento de los procesos decisorios, y el estatus asociativo de estos entes y su ausencia de carácter oficial (Urteaga 2004b: 135-152). 
el ex-primer ministro británico, Tony Blair, y el senador norteamericano, George Mitchell, aportan igualmente su apoyo a esta iniciativa (Enbata 2011).

En esta Conferencia participan asimismo los principales actores políticos y sindicales del País Vasco, de ambos lados de la frontera, y desemboca en la lectura de un comunicado que consta de cinco puntos:

1. «Llamamos a ETA a hacer una declaración pública de cese definitivo de la actividad armada y a solicitar diálogo a los gobiernos de España y Francia para tratar exclusivamente las consecuencias del conflicto.

2. Si dicha declaración fuese realizada, instamos a los gobiernos de España y Francia a darla la bienvenida y a aceptar iniciar conversaciones para tratar exclusivamente las consecuencias del conflicto.

3. Instamos a que se [den] pasos profundos para avanzar en la reconciliación; reconocer, compensar y asistir a todas las víctimas; reconocer el dolor causado y ayudar a sanar las heridas personales y sociales.

4. Sugerimos que los actores no-violentos y representantes políticos se reúnan y discutan cuestiones políticas, así como otras relacionadas con el respeto, con consulta a la ciudadanía, lo cual podría contribuir a una nueva era sin conflicto. (...) El diálogo también podría ser asistido por facilitadores internacionales si así fuese decidido por las partes involucradas.

5. Estamos dispuestos a organizar un comité de seguimiento de estas recomendaciones» (Bake Bidea 2021b).

Cuarenta y ocho horas más tarde, el 20 de octubre, respetando los compromisos adquiridos ante la comunidad internacional, la organización armada vasca publica un comunicado respondiendo favorablemente a esta demanda (Urteaga 2017: 178).

\subsection{Bake Bidea y la Declaración de Baiona}

A fin de consolidar el proceso de paz, se constituye en el País Vasco norte la plataforma ciudadana Bake Bidea², con el fin de «impulsar la reflexión sobre el proceso de paz a través del diálogo con la sociedad

2 Véase su página web: http://www.bakebidea.com 
civil» (Lokarri 2013). Los miembros de Bake Bidea provienen de la Liga por los Derechos Humanos, la Cimade, Anai Artea, el Comité de Defensa de los Derechos Humanos del País Vasco, los sindicatos CFDT, Solidaires, CGT y LAB, y de partidos políticos como Abertzaleen Batasuna, Batasuna, NPA y EELV.

En diciembre de 2012, Bake Bidea, en colaboración con Lokarri y la Facultad Multidisciplinar de Baiona de la Universidad del Pau y de los Países del Adur, organiza el Foro para la Paz. Esta iniciativa ofrece la oportunidad de dar a conocer la reflexión llevada a cabo tanto en el País Vasco como a nivel internacional, al conjunto del territorio y, en particular, a los actores sociales, económicos y políticos de Iparralde (Lokarri 2013).

En 2013, Bake Bidea, en cooperación con el Foro Social impulsado por Lokarri, anuncia la constitución de una comisión encargada de promover el proceso de paz iniciado en Aiete. Está compuesta por ocho personas: los magistrados Garbiñe Biurrun y Henri Duhault, los periodistas Anne-Marie Bordes y Maite Pérez, los abogados Nazario Oleaga y Michel Tubiana, y los expertos en derechos humanos Jordi Armadans y Fernando Arlendariz. El objetivo principal de esta comisión es supervisar la implementación de las recomendaciones formuladas por el Foro para la Paz reuniéndose con las instituciones, los partidos políticos y todos los demás actores implicados en el proceso de paz. Se trata de "facilitar, animar e impulsar una amplia y activa participación de las instituciones, de los partidos políticos y de la sociedad civil en el proceso» (El Diario Norte 2013).

Gracias al trabajo llevado a cabo por Bake Bidea

y a la interlocución constante mantenida entre los principales actores del territorio, los partidos políticos, sindicatos y asociaciones del País Vasco norte se ponen de acuerdo sobre una declaración común que tiene como finalidad realizar una contribución al proceso de paz. La Declaración de Baiona es presentada al público el 14 de octubre de 2014.

Sus firmantes recuerdan que, como «representantes electos del País Vasco [norte] para algunos y en representación de sus partidos para otros, [han] aprobado, a título personal o en nombre de sus organizaciones respectivas, la Declaración de Aiete y los puntos que contiene, como una hoja de ruta transitoria y válida para construir la paz. Es la razón que los ha llevado a reunirse y a trabajar desde entonces, unidos por el fuerte compromiso de realizar una contribución al proceso de paz iniciado tras la declaración de alto el fuego de la actividad armada de ETA el 20 de octubre de 2011. Durante ese proceso de diálogo, han profundizado en los puntos de la Declaración 
de Aiete y [han] analizado su [posible] aportación a ese proceso de paz» (CSPB 2014).

El documento presentado refleja el consenso alcanzado sobre diversos puntos y contiene propuestas susceptibles de conseguir un amplio consenso en la sociedad vasca. Entre los firmantes figuran JeanRené Etchegaray, alcalde de Baiona; Kotte Ecenarro, alcalde de Hendaia y vice-presidente del Consejo general de los Pirineos-Atlánticos; Max Brisson, consejero general y concejal de Biarritz; Frédérique Espagnac, senadora de los Pirineos-Atlánticos; Jean-Jacques Lasserre, senador de los Pirineos-Atlánticos, consejero general y presidente del Consejo de Electos del País Vasco; Xabi Larralde, responsable de Sortu en el País Vasco norte; Jakes Bortayrou, representante de Abertzaleen Batasuna; Michel Larralde, secretario general del sindicato CFDT en Iparralde; o Jean Lissar, portavoz de EELV en el territorio (CSPB 2014).

Los firmantes estiman que las cuestiones a abordar en este proceso de discusión podrían ser las siguientes:

- Marco jurídico actual y de respeto de los derechos humanos: recomiendan la aproximación y la agrupación de los presos y la aplicación sin restricciones de los derechos reconocidos a las personas detenidas, a los presos ya juzgados y a los reclusos en espera de juicio; la ampliación del abanico de personas beneficiarias de una medida de libertad condicional o provisional, y la elaboración por las administraciones públicas de un plan de inserción social de presos.

- Consenso político y marco jurídico renovado: sugieren la puesta en marcha de una instancia ad hoc para decidir sobre: 1) las condiciones de liberación de los presos condenados que no pueden solicitar una medida de liberación condicional y de los detenidos en espera de juicio que no pueden beneficiarse de una medida de libertad provisional; 2) la aplicación a los refugiados de la libre elección de su lugar de residencia; 3) la suspensión de los procedimientos judiciales y policiales contra miembros de ETA y la toma en consideración de su situación específica; 4) la exclusión de los delitos políticos en la puesta en marcha de las euroórdenes; $y, 5)$ la aplicación de un régimen transitorio derogatorio en la aplicación de las euroórdenes para los casos vinculados con el conflicto vasco. A medio plazo, proponen la aprobación de una ley de amnistía para los asuntos asociados al mismo.

- Fin de la actividad armada de ETA: proponen un acuerdo entre el gobierno y ETA, bajo control internacional, para definir y 
crear las condiciones y los procedimientos del desarme y del desmantelamiento de las infraestructuras de ETA en Francia. Asimismo, debería ser puesta en marcha una comisión de expertos de tipo «Verdad y Reconciliación» a fin de poner de manifiesto los casos vinculados con el conflicto vasco, establecer un reconocimiento recíproco del sufrimiento de todas las víctimas y definir las diferentes formas de reparación.

Los firmantes de la Declaración de Baiona estiman, además, que la cuestión de la reconciliación debería ser abordada desde el inicio del proceso de paz y llevada a cabo en el respeto de los ritmos de cada uno de los actores implicados. Consideran igualmente que ese proceso necesitaría el compromiso de los gobiernos (CSPB 2014).

\subsection{El desarme y la disolución de ETA}

Ante la constatación de una cierta parálisis, dado que los Estados francés y español no inician ningún proceso negociador con la organización armada para solucionar las consecuencias del conflicto, cinco personas conocidas como los Artesanos de la Paz toman la iniciativa de entrar en contacto con ETA a fin de proceder a su desarme parcial a través de la sociedad civil (Esnaola 2017). Esto desemboca, el 16 de diciembre de 2016, en la operación de Luhusoa, que se traduce en la detención por los inspectores de la Policía Judicial, apoyados por policías del RAID y agentes de la Guardia Civil, de personalidades reconocidas del nacionalismo vasco, tales como Michel Berhocoirigoin, Jean-Noël Etcheverry, Michel Bergouignan o Béatrice Molle-Haran, quienes tenían previsto destruir una parte del arsenal de ETA (estimado en el $15 \%$ del total).

Previamente a su detención, los Artesanos de la Paz habían enviado a los medios de comunicación locales y estatales sendos comunicados en los cuales explicaban los motivos de su acto. Esto creó un movimiento de apoyo de los electos locales, sean cual sean sus partidos de pertenencia, y de los actores de la sociedad civil organizada del País Vasco norte, lo que dio lugar a posicionamientos públicos y a una movilización masiva en las calles de Baiona el 17 de diciembre de 2017 que reunió a 4.000 personas. Los medios de comunicación del Hexágono dieron cuenta igualmente de los acontecimientos, cuestionando la pertinencia de esta operación policial y subrayando el perfil de las personas detenidas. Esto condujo a los magistrados encargados del caso a decidir su puesta en libertad bajo control judicial. 
La operación de Luhusoa puso en el centro de la agenda política gala la cuestión del proceso de paz en general, y la del desarme de ETA en particular.

Posteriormente, tras múltiples discusiones, ETA procede a su desarme el 8 de abril de 2017. La organización informa a los Artesanos de la Paz de la ubicación precisa de sus arsenales, previamente inventariados, sellados, y situados en escondites seguros.

En el Ayuntamiento de Baiona, en presencia del presidente de la CAPV y de testigos internacionales, Jean-Noël Etcheverry entrega los datos con la ubicación precisa de los escondites de armas a través de sus coordenadas GPS y fotos a Harold Good y Matteo Zuppi, que los trasladan a su vez a los representantes de la Comisión Internacional de Verificación, liderada por Ram Manikkalingam. Estos últimos los transmiten inmediatamente a las autoridades judiciales galas a fin de que estas puedan ordenar a la Policía Judicial proceder a la recuperación de las armas de ETA; sabiendo que las sustancias peligrosas serán destruidas y las armas y materiales encontrados serán analizados. Todo ello acontece sin sobresaltos ni enfrentamientos, de tal forma que el ministro del Interior francés, Matthias Fekl, expresa públicamente su satisfacción en cuanto al desarrollo del desarme. Poco después, una rueda de prensa tiene lugar en el Ayuntamiento de la capital labortana, antes de que una gran concentración popular, que reúne a 20.000 personas, se produzca en las calles de Baiona. Los medios de comunicación de ámbito local, estatal e internacional se hacen eco de este acontecimiento histórico.

No en vano, los Artesanos de la Paz desean llevar el proceso de paz hasta su término, lo que implica tejer nuevas alianzas y beneficiarse del apoyo de numerosos actores, sociales e institucionales, locales y hexagonales. Como consecuencia de ese esfuerzo, el 22 de noviembre de 2017, el Consejo de París aprueba, de manera unánime, una resolución de apoyo al proceso de paz en el País Vasco y a la manifestación del 9 de diciembre de ese mismo año (Mediabask 2017).

Luego, en vísperas de la Conferencia Internacional de Arnaga, el 3 de mayo de 2018, ETA anuncia su disolución a través de un comunicado, poniendo así fin «al ciclo histórico y a la función de la organización». Indica claramente que "ha desmantelado completamente sus estructuras» y "ha puesto fin a toda su actividad política» (Enbata 2018). Al día siguiente, a invitación de Bake Bidea, del Foro Social y del GIC, mediadores internacionales, representantes políticos, sindicales y asociativos se reúnen en Kanbo para dar la bienvenida al comunicado final de ETA y apostar por la reconciliación (Bake Bidea 2021c). 


\subsection{La construcción de la convivencia}

Una vez ETA desarmada y disuelta, queda por construir una convivencia perenne, lo que implica resolver la cuestión de los presos vascos. Así, tras el desarme del 8 de abril de 2017, los Artesanos de la Paz lanzan una serie de movilizaciones para incitar a los gobiernos francés y español a flexibilizar sus políticas penitenciarias respectivas, sinónimo de aproximación de los presos a unas cárceles próximas al País Vasco, retirada del estatus DPS, liberación de los presos gravemente enfermos y de cierta edad, libertad condicional concedida a las largas condenas, etc. Entre ellas, la manifestación del 9 de diciembre de 2017 en París representa un momento clave, y pone de manifiesto el amplio consenso existente [en el País Vasco norte a propósito] de una resolución global del conflicto (Larralde 2017).

Esta movilización masiva, que reunió a 10.000 personas en las calles de la capital gala, va a favorecer las negociaciones iniciadas en julio de 2017 entre una delegación del País Vasco norte, liderada por Jean-René Etchegaray, y el ministerio de Justicia francés, y que desemboca en la flexibilización de la política penitenciaria. En pocos meses, 25 de los 56 presos vascos encarcelados en cárceles francesas son trasladados a los centros penitenciarios de Mont-de-Marsan y Lannemezan. Asimismo, 22 de los 36 estatus DPS son retirados, lo que favorece la aproximación de estos reos y la obtención de beneficios penitenciarios. Por último, tres reclusos y dos detenidas son liberados (Enbata 2019).

Este proceso se interrumpe, sin embargo, a partir del mes de julio de 2018, tras la llegada al poder en España de Pedro Sánchez y, sobre todo, del nombramiento de Fernando Grande-Marlaska como ministro de Interior. Este último, antiguo presidente de la Sala de lo penal de la Audiencia Nacional, encargada de juzgar los casos relacionados con ETA, es especialmente sensible al discurso de ciertas asociaciones de víctimas del terrorismo, tales como AVT. Pero, los problemas persisten:

3 presos están solos, 10 [detenidas] carecen de solución para poder [ser trasladadas] a un centro penitenciario próximo al País Vasco y están repartidas en cuatro centros diferentes, 41 [reclusos] están dispersados en ocho centros de detención, (...) [y] 3 de ellos iniciarán su trigésimo año de reclusión tras recibir numerosos rechazos de puesta en libertad condicional (Enbata 2019).

Esto conduce a la delegación de Iparralde a redoblar sus esfuerzos a fin de convencer, especialmente a Davos, directora adjunta del gabinete del ministro encargada de las negociaciones con los electos 
vascos y los Artesanos de la Paz, de continuar el proceso iniciado. Es cuestión de reclamar "la aplicación del derecho [ordinario] para los presos vascos y el fin [de las] medidas de excepción» (Enbata 2019).

Ante esta situación de bloqueo, electos y representantes de la sociedad civil organizada local vuelven a movilizarse. Así, el 5 de enero de 2019, más de 70 electos del País Vasco norte participan en la rueda de prensa mostrando su apoyo a la movilización convocada por los Artesanos de la Paz, el 12 de enero en Baiona.

Deseando construir un porvenir sereno y apaciguado para el País Vasco, los participantes [hacen un llamamiento] al gobierno francés a fin de restablecer las bases del diálogo iniciado (...), un diálogo necesario para la puesta en marcha de un proceso de paz sólido y duradero en el País Vasco (Aizpuru 2019).

Esta manifestación reúne a 9.000 personas en las calles de Baiona, mientras que una movilización similar tiene lugar simultáneamente en Bilbao con la participación de 76.000 individuos.

Posteriormente a estas manifestaciones masivas, las discusiones se reanudan entre la delegación del País Vasco norte y el ministerio de Justicia galo. Esto desemboca en la retirada del estatus DPS a seis detenidos adicionales y en el traslado a las cárceles de Mont-deMarsan y Lannemezan de cinco presos; sin contar la problemática de las nueve detenidas vascas dispersadas en tres cárceles del Hexágono y para quienes no existe ninguna cárcel central próxima al País Vasco (Etxeberri 2019).

La construcción de una convivencia perenne y sólida implica igualmente prestar atención a las víctimas, garantizándoles verdad, justicia y reparación. Así, desde el mismo día del desarme de ETA, los Artesanos de la Paz subrayan la necesidad de reconocer a todas las víctimas. El Manifiesto de Baiona del 8 de abril de 2017 es explícito a ese respecto (Mediabask 2017b). Y, por ello, a partir del mes de mayo, anuncian la puesta en marcha de un grupo de trabajo sobre las víctimas, que aspira a conocer mejor esta problemática tan compleja, los actores y las experiencias en curso, en el respeto absoluto de todos. Es cuestión de tener en cuenta a todas las víctimas de violaciones de derechos humanos.

Esto desemboca en el Foro organizado por Bake Bidea un año después del desarme, a fin de realizar un balance y poner de manifiesto los retos y las perspectivas de futuro. La situación de los presos y de las víctimas se encuentra en el centro de los debates; sabiendo que «hablar de las víctimas no [significa] olvidar a los presos. Y hablar de 
los presos no implica olvidar a las víctimas» (Molle-Haran 2018a). Es cuestión, sobre todo, de mencionar las iniciativas pioneras, tales la llevada a cabo por el alcalde de Rentería. Una iniciativa basada en la búsqueda de consenso y que aspira a construir una convivencia entre los diversos protagonistas del conflicto, que exige una total discreción durante los primeros encuentros entre las víctimas, dando lugar, más tarde, a homenajes oficiales a las familias de las víctimas de ETA así como a aquellas de la policía española (Molle-Haran 2018a). El Foro concluye con la inauguración de la escultura Arbolaren Egia en la explanada Roland Barthes de Baiona.

Posteriormente, algunos días antes de su disolución definitiva, ETA publica un comunicado en el cual dice ser perfectamente consciente de que, durante este largo periodo de lucha armada, ha provocado mucho dolor, mucho daño que no tiene solución. Y desea expresar su respeto hacia los muertos, los heridos y las víctimas que ha causado. Además, la organización armada pide perdón a las víctimas que no han tenido una participación directa en el conflicto (Molle-Haran 2018b).

La Conferencia Internacional de Kanbo, que se desarrolla al día siguiente de la disolución de ETA, empieza con un minuto de silencio en memoria de todas las víctimas del conflicto. De hecho, en el centro de esta jornada se sitúa la búsqueda de la reconciliación entre las diversas partes, la memoria y el reconocimiento de todas las víctimas del conflicto (Molle-Haran 2018c). Y la Declaración de Arnaga insiste en que son necesarios unos esfuerzos adicionales para reconocer y ayudar a todas las víctimas (Mediabask 2018).

Etxerat expresa, de su parte, su empatía hacia las víctimas de todas las violencias, apostando por la convivencia. Esta asociación de familiares de presos vascos expresa sus más sinceras excusas, porque, sin ser consciente de ello, ha podido, por su distancia, contribuir más aún al dolor que deben afrontar las víctimas de ETA, causado por la pérdida de un familiar de manera violenta (Molle-Haran 2019). Asimismo, Etxerat dice reconocer, respetar y tener empatía hacia todas las víctimas de las diferentes expresiones de violencia, y no desear establecer una equivalencia entre los sufrimientos, pudiendo y comprender a aquellos que lo padecen. Desea, por último, tender puentes, hacer de tal forma que diferentes relatos puedan coexistir, a fin de cerrar las heridas y construir una verdadera convivencia (Molle-Haran 2019).

Por último, el 7 de junio de 2019, Bake Bidea y los Artesanos de la Paz organizan en Biarritz una conferencia sobre la paz, prestando particular atención a las víctimas, en la que reúnen a víctimas de ETA y del terrorismo de Estado. Asimismo, insisten en la necesidad de «verdad y justicia» (Mediabask 2019). 


\section{Conclusión}

La nueva gobernanza concebida e implementada en el País Vasco norte desde inicios de los años noventa ha propiciado un cambio progresivo de la cultura política local basada, actualmente, en el diálogo, la negociación y el acuerdo. Gracias a ella, amplios consensos, tanto políticos como sociales, han sido posibles en temas tan relevantes como la institucionalización del territorio y el proceso de paz. Esto ha posibilitado el hecho de que en este territorio, escasamente poblado y que solo goza de una institución específica desde 2017, se haya producido el desarme y la disolución de ETA, la flexibilización de la política penitenciaria y la construcción progresiva de una convivencia basada en el reconocimiento, la justicia y la reparación para todas las víctimas.

Aún queda mucho camino por recorrer y los actores implicados en este proceso de paz son plenamente conscientes de ello. Además de la situación de los presos encarcelados lejos del País Vasco y de aquellos que cumplen largas penas o que están enfermos, se halla el escaso reconocimiento de ciertas víctimas y la ausencia de justicia y reparación para muchas de ellas. A su vez, la construcción de una memoria colectiva inclusiva y compartida en la que caben todos los relatos sigue siendo una tarea pendiente. Se trata de un largo proceso, propiciado por el paso del tiempo y el relevo generacional, que puede ser favorecido tanto por las administraciones públicas como por los actores de la sociedad civil organizada, a través de un debate respetuoso y de una transmisión efectiva tanto por medio del sistema educativo y los medios de comunicación, como por medio del diálogo intergeneracional.

En efecto, para crear las condiciones de la no-repetición de los episodios de violencia padecidos durante varias décadas, es preciso que las nuevas generaciones tengan un conocimiento pormenorizado de lo acontecido y estén sensibilizadas hacía él. Esto implica llevar a cabo una doble labor de historia y de memoria. Por una parte, dado que las nuevas generaciones no han experimentado directamente los episodios más violentos del conflicto, es imprescindible dar a conocer, de la manera más objetiva e integral posible, los principales actores, acontecimientos y circunstancias para que puedan hacerse una idea más detallada de lo sucedido. Por otra parte, puesto que el mero conocimiento histórico es insuficiente, debe ser completado por un relato personalizado, contado por los propios actores implicados, que haga intervenir las vivencias, los sentimientos y las emociones. Esa dimensión más subjetiva e íntima propicia la concienciación y la empatía hacia las víctimas. 


\section{Bibliografía}

Ahedo, Igor y Urteaga, Eguzki. 2005. Gobernanza y territorio en Iparralde. Vitoria: Cuadernos Sociológicos Vascos.

Aizpuru, Ainhoa. 2019. "Les élus du Pays Basque se mobilisent en vue de la manifestation», Mediabask, 10 de enero.

Bake Bidea. 2014. Groupe de dialogue dans le Pays Basque de France. Acceso el 22/12/2020. http://www.bakebidea.com/wp-content/uploads/2016/04/ Groupe-de-dialogue-dans-le-Pays-Basque-de-France.pdf

Bake Bidea. 2021a. Espace de travail sur la question des prisonniers basques entre le ministère de la Justice français et la délégation du Pays Basque. Acceso el 22/12/2020. http://www.bakebidea.com/?page_id=5636

Bake Bidea. 2021b. Déclaration Internationale d'Aiete. Acceso el 22/12/2020. http://www.bakebidea.com/wp-content/uploads/2016/04/ D\%C3\%A9claration-internationale-d.pdf

Bake Bidea. 2021c. Déclaration d'Arnaga. Acceso el 22/12/2020. http://www. bakebidea.com/wp-content/uploads/2016/04/ARNAGA_FRA.pdf

Bidegain, Eneko. 2007. Iparretarrak. Histoire d'une organisation politique armée. Bayonne: Gatuzain.

Bourdin, Alain. 2000. «Gouvernance». En Repenser le territoire: un dictionnaire critique, dirigido por Serge Wachter et. al., 42-43. La Tour d'Aigues: DATAR/Editions de l'Aube.

Cervera-Marzal, Manuel. 2013. Désobéir en démocratie. La pensée désobéissante de Thoreau à Martin Luther King. Bussy-Saint Martin: Aux Forges de Vulcain.

Chaussier, Jean-Daniel. 1997. Quel territoire pour le Pays Basque? Les cartes de l'identité. París: L'Harmattan.

Chaussier, Jean-Daniel. 1998. "La question territoriale en Pays Basque de France», en La construcción del espacio vasco-aquitano. Un estudio multidisciplinar, dirigido por Francisco Letamendia, Leioa: UPV

Club de Prospective Pays Basque. 1994. Le Pays Basque en perspective. Acceso el 22/12/2020. http://www.lurraldea.net/fileadmin/Bibliodocs/ synthese2010.pdf

Collectivité Territoriale Pays Basque. 2013. Un projet partagé. Acceso el 22/12/2020. http://www.ctpb.org

Conseil de Développement du Pays Basque. 1994. Statuts. Conseil de Développement du Pays Basque. Bayonne: Sous-préfecture de Bayonne.

Conseil de Développement du Pays Basque. 1996. Schéma d'Aménagement et de Développement du Pays Basque. Acceso el 22/12/2020. http://www. lurraldea.net/uploads/media/schema.pdf

Conseil de Développement du Pays Basque. 2000. Evaluation du Schéma de Développement et d'Aménagement du Pays Basque. Acceso el 22/12/2020. http://www.lurraldea.net/fileadmin/Bibliodocs/evalSADPB.pdf

Conseil de Développement du Pays Basque. 2001. Préfiguration des territoires de développement infra-Pays Basque. Sablons: Chez L'Auteur 
Conseil de Développement du Pays Basque. 2007. Pays Basque 2020. Acceso el 22/12/2020. http://www.lurraldea.net/fr/pays-basque-territoire-deprojet/telecharger-le-rapport-pays-basque-2020-euskal-herria-2020txostena-jeisteko.html

Conseil des Elus du Pays Basque. 1995. Statuts. Conseil des Elus du Pays Basque. Bayonne: Sous-préfecture de Bayonne.

Contrat territorial Pays Basque 2007-2013. 2008. Acceso el 22/12/2020. http:// www.lurraldea.net/fileadmin/documents/Contrat\%20territorial-fr.pdf

Contrat Territorial Pays Basque 2015-2020. 2015. Acceso el 22/12/2020. http://www.lurraldea.net/fileadmin/Bibliodocs/avis_cdpb/CTPB\%2020152020DVavecTABLEAU\%20.pdf

Convention Specifique Pays Basque 2001-2006. 2000. Acceso el 22/12/2020. http://www.lurraldea.net/fileadmin/Bibliodocs/conv-spedec01.pdf

CSPB. 2014. 24 octobre 2014: Déclaration de Bayonne. Acceso el 22/12/2020. cspb.unblog.fr/2014/11/06/24-octobre-2014-declaration-de-bayonne/

Chautard, Guy, Bruno Villalba y Bertrand Zuindeau. 2010. "Gouvernance locale et développement durable», Développement durable et territoires, dossier 2/2003.

Desjeux, Dominique, Isabelle Garabuau-Moussaoui y Sophie Alami. 2019. Les méthodes qualitatives. París: PUF.

Diez, Thomas, Ingvild Bode y Aleksandra Fernandes da Costa. 2011. Key concepts in international relations. Londres: Sage.

El Diario Norte 2013. «El Foro Social de Lokarri y Bake Bidea promueve una comisión de ocho personas para impulsar el proceso de paz», eldiario.es, 23 de diciembre. Acceso el 22/12/2020. https://www.eldiario.es/euskadi/ euskadi/foro-social-lokarri-bake-bidea_1_5105218.html

Enbata 2011. «ETA arrête définitivement son activité armée», 9 de noviembre.

Enbata 2018. «Dernier communiqué d'ETA», junio.

Enbata 2019. «La mobilisation continue pour les prisonniers», enero.

Esnaola, Enekoitz. 2017. Luhuso. ETA-ren armagabetze zibilaren kontakizuna. Donostia: Elkar-Berria-Jakin.

Etxeberri, Antton. 2019. «Hélène Davos quitte ses fonctions», Mediabask, 25 de julio.

Fisas, Vicenç. 2010. «Introducción a los procesos de paz», Quaderns de construcción de pau 12.

Foro Social. 2017. El modelo vasco de desarme. Lecciones aprendidas de un proceso innovador. Acceso el 22/12/2020. http://forosoziala.eus/ files/posts/2020/f95f60b4a67382e757d51bf298a4ed2carmagabetzeadesarme-desarmement-copia-compressedpdf.pdf

Jouve, Bernard. 2003. La gouvernance urbaine en question. París: Elsivier.

Lallement, Michel. 2015. "Max Weber (1864-1920). Une méthode compréhensive», Sciences Humaines, 20. Acceso el 22/12/2020. https:// www.scienceshumaines.com/max-weber-1864-1920-une-methodecomprehensive_fr_34455.html

Larralde, Xabi. 2017. «Les presos, c'est maintenant!», Enbata, diciembre. 
Le Gàles, Patrick. 1995. «Du gouvernement des villes à la gouvernance urbaine», Revue française des sciences politiques, 45(1): 57-95.

Leloup, Fabienne, Laurence Moyart y Bernard Pecqueur. 2005. «La gouvernance territoriale comme nouveau mode de coordination territoriale? », Géographie, économie, société, 7(4): 321-332. Acceso el 22/12/2020. https://www.cairn.info/revue-geographie-economie-societe2005-4-page-321.htm

L'Express. 2018. «ETA: dernier acte de la dissolution au Pays Basque français», L'Express, 4 de mayo. Acceso el 22/12/2020. https://www.lexpress.fr/ actualites/1/societe/dernier-acte-de-la-dissolution-de-l-eta-au-pays-basquefrancais_2005799.html

Lokarri. 2013. Bake Bidea. Acceso el 22/12/2020. www.forosocialpaz.org/ entidades-organizadoras/bake-bidea/

Loyer, Barbara. 2003. «Identités et pouvoir local: le cas de la revendication d'un Département Pays Basque», Hérodote 110: 103-128.

Mediabask. 2017. «Manifeste de Bayonne 8 avril 2017», Mediabask,13 de abril.

Mediabask. 2018. «Déclaration d'Arnaga», Mediabask, 9 de mayo.

Mediabask. 2019. "Des victimes, une même soif de reconnaissance», Mediabask, 13 de junio.

Molle-Haran, Béatrice. 2018a. «Jean-René Etchegaray: la paix n'est pas un acte passif», Mediabask, 12 de abril.

Molle-Haran, Béatrice. 2018b. «ETA exprime son respect envers les victimes et reconnaît le mal causé», Mediabask, 26 de abril.

Molle-Haran, Béatrice. 2018c. "C'est un moment historique pour l'Europe entière», Mediabask, 9 de mayo.

Molle-Haran, Béatrice. 2019. «Etxerat présente ses excuses aux victimes d'ETA», Mediabask, 7 de marzo.

Moruzzi, Jean-François y Emmanuel Boulaert. 1988. Iparretarrak: séparatisme et terrorisme en Pays Basque français. París: Plon.

Munarriz, Begoña. 1992. "Técnicas y métodos en investigación cualitativa», en Metodología educativa, dirigido por Eduardo Abalde y Jesús M. Muñoz, 101-116. Coruña: Universidad de Coruña.

Murua, Imanol. 2015. Ekarri armak. Donostia: Elkar-Berria.

Murua, Imanol. 2016. Ending ETA's armed campaign. How and why the Basque armed group abandoned violence. Londres: Routledge.

Observatoire International des Prisons. 2014. "Détenus particulièrement signalés: surveillance permanente et contrainte maximale», OIP, 12 de julio. Acceso el 22/12/2020. https://oip.org/analyse/detenusparticulierement-signales-surveillance-permanente-et-contrainte-maximale/

Pasquier, Romain, Vincent Simoulin y Julien Weisbein (dir.). 2007. La gouvernance territoriale. Pratiques, discours et théories. París: LGDJ.

Pecqueur, Bernard. 2000. Le développement local. París: Syros.

Stoker, Gerry. 1998. "Cing propositions pour une théorie de la gouvernance», Revue Internationale des Sciences Sociales 155: 19-30.

Urteaga, Eguzki. 2004a. La question basque en France. Toulouse: Milan. 
Urteaga, Eguzki. 2004b. La politique linguistique au Pays Basque. París: L'Harmattan.

Urteaga, Eguzki. 2007. Le vote nationaliste basque. París: L'Harmattan.

Urteaga, Eguzki. 2017. La Communauté Pays Basque. L'institutionnalisation du territoire. París: L'Harmattan.

Urteaga, Eguzki. 2019. La nouvelle politique linguistique au Pays Basque. París: L'Harmattan.a

Urteaga, Eguzki. 2020a. La politique d'aménagement et de développement du Pays Basque. París: L'Harmattan.

Urteaga, Eguzki. 2020b. L'essor du vote nationaliste basque. París: L'Harmattan.

Urteaga, Eguzki. 2021. La politique culturelle au Pays Basque. París: L'Harmattan.

Urteaga, Eguzki e Igor AHEDO. 2004. La nouvelle gouvernance en Pays Basque. París: L'Harmattan.

Zin, Howard. 2010. Désobéissance civile et démocratie. Marseille: Agone. 


\section{Copyright}

Deusto Journal of Human Rights / Revista Deusto de Derechos Humanos is an Open Access journal; which means that it is free for full and immediate access, reading, search, download, distribution, and reuse in any medium only for non-commercial purposes and in accordance with any applicable copyright legislation, without prior permission from the copyright holder (University of Deusto) or the author; provided the original work and publication source are properly cited (Issue number, year, pages and DOI if applicable) and any changes to the original are clearly indicated. Any other use of its content in any medium or format, now known or developed in the future, requires prior written permission of the copyright holder.

\section{Derechos de autoría}

Deusto Journal of Human Rights / Revista Deusto de Derechos Humanos es una revista de Acceso Abierto; lo que significa que es de libre acceso en su integridad inmediatamente después de la publicación de cada número. Se permite su lectura, la búsqueda, descarga, distribución y reutilización en cualquier tipo de soporte sólo para fines no comerciales y según lo previsto por la ley; sin la previa autorización de la Editorial (Universidad de Deusto) o la persona autora, siempre que la obra original sea debidamente citada (número, año, páginas y DOI si procede) y cualquier cambio en el original esté claramente indicado. Cualquier otro uso de su contenido en cualquier medio o formato, ahora conocido o desarrollado en el futuro, requiere el permiso previo por escrito de la persona titular de los derechos de autoría. 